\title{
Bergen İş Bağımlılığı Ölçeği’nin Türkçeye Uyarlanması: Geçerlik ve Güvenirlik Sınama Çalışması
}

\section{Adaptation of the Bergen Work Addition Scale into Turkish: A Validity and Reliability Testing Study}

\author{
Emrah Özsoy ${ }^{1}$ @]
}

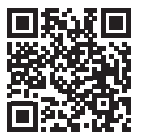

'Dr. Öğretim Üyesi, Sakarya Üniversitesi İşletme Fakültesi, İşletme Bölümü, Sakarya, Türkiye

ORCID: E.Ö. 0000-0003-2886-8824

Sorumlu yazar/Corresponding author: Emrah Özsoy,

Sakarya Üniversitesi İşletme Fakültesi, İşletme Bölümü, Sakarya, Türkiye

E-posta/E-mail: eozsoy@sakarya.edu.tr

Başvuru/Submitted: 09.01.2019 Revizyon Talebi/Revision Requested: 11.01.2019

Son Revizyon/Last Revision Received: 23.10.2019

Kabul/Accepted: 12.11.2019

Online Yayın/Published Online: 09.04 .2020

Atıf/Citation: Ozsoy, E. (2020). Adaptation of the Bergen work addition scale into Turkish: A validity and reliability testing study. Psikoloji Çalışmaları - Studies in Psychology. Advance online publication. https://doi.org/10.26650/SP2019-0002

\begin{abstract}
ÖZ
Bu çalışmada Andreassen, Griffiths, Hetland ve Pallesen (2012) tarafindan geliştirilmiş Bergen İş Bağımlılı̆̆ı Ölçeği’nin (Bergen Work Addiction Scale, BWAS) Türkçeye uyarlanması, geçerlik ve güvenirliğinin sınanması amaçlanmıştır. Bu kapsamda BWAS'ın Türkçe formunun (BWAS-T) faktör yapısı (doğrulayıcı faktör analizi), yapı geçerliği (yakınsak geçerlik ve diğer yapılarla ilişkiler) ve güvenirliği (içsel tutarlılık) test edilmiştir. Ölçeğin yakınsak geçerliğinin sınanması için BWAS-T’nin, DUWAS İşkoliklik Ölçeği’nin Türkçe formu ile ilişkisi incelenmiştir. Ölçeğin diğer yapılarla ilişkisinin sınanması için iş stresi, iş tatmini, yaşam tatmini ve haftalık ortalama çalışma saati ile ilişkisi incelenmiş̧ir. Ölçeğin özellikleri dilsel eşdeğerlik, madde analizi, yapı geçerliği ve Cronbach Alpha güvenirlik analizi yöntemleriyle sınanmıştır. Araştırmaya çeşitli sektörlerde çalışan 294 işgören katılmıştır. Araştırma bulgularına göre BWAS-T'nin faktör yapısına ilişkin elde edilen uyum indeksleri değerlerinin kabul edilebilir aralıkta olduğu ve orijinali ile uyumlu bir şekilde tek faktörlü yapısının desteklendiği tespit edilmiştir. Doğrulayıcı faktör analizi bulguları, $\chi^{2}=45.916, p$ $<.001, \chi^{2} / \mathrm{df}=3.53, \mathrm{TLI}=.88, \mathrm{CFI}=.93, \mathrm{GFI}=.96, \mathrm{AGFI}=.91, \mathrm{RMSEA}=.07$ şeklindedir. BWAS-T'nin içsel tutarlılık değeri .78 olarak hesaplanmış ve ölçeğin güvenirliğinin kabul edilebilir düzeyde olduğu sonucuna varılmıştır. BWAS-T’nin DUWAS-TR'nin toplam skoru ve DUWAS-TR'nin alt faktörleri (aşırı çalışma ve kompulsif çalışma) ile pozitif ilişkili olduğu ve yakınsak geçerliğinin desteklendiği sonucuna varılmıştır. Beklenildiği üzere BWAS-T, iş stresi ile pozitif iş tatmini ve yaşam tatmini ile de negatif bir ilişki sergilemiş̧ir. Ayrıca BWAS-T ve DUWASTR, iş stresi, iş tatmini, yaşam tatmini ve haftalık ortalama çalışma saati ile benzer etki büyüklüğünde korelasyon sergilemiştir. Tüm bu bulgulara dayanarak BWAST’nin psikometrik özelliklerine yönelik çeşitli kanıtlar elde edilmiş bir ölçüm aracı olduğu söylenebilir.
\end{abstract}

Anahtar Kelimeler: İşkoliklik, iş bağımlılı̆̆ı, Bergen iş bağımlılı̆̆ı ölçeği, geçerlik, güvenirlik 


\section{ABSTRACT}

This study aimed to adapt the Bergen Work Addiction Scale (BWAS) developed by Andreassen, Griffiths, Hetland and Pallesen (2012) into Turkish and to test its validity and reliability. In this context, the factor structure (confirmatory factor analyses), construct validity (convergent validity and relations with other structures), and reliability (internal consistency) of the Turkish version of BWAS (BWAS-T) were tested. In order to test the convergent validity of the scale, the relationship of BWAS-T with a Turkish form of the Dutch Work Addiction Scale was examined. To test the relationship of the scale with other structures, the relationship of BWAS-T with job stress, job satisfaction, life satisfaction, and weekly average working hours was examined. The properties of the scale were tested with linguistic equivalence, item analysis, construct validity, and Cronbach Alpha reliability analysis methods. Two hundred ninety-four employees working in various sectors participated in the study. According to the findings of the study, it was determined that the values of the fit indices obtained for factor structure of BWAS-T were within an acceptable range and that the one-factor structure was supported in accordance with the original study. Confirmatory factor analysis findings were $\chi^{2}$ $=45.916, p<.001, \chi^{2} / \mathrm{df}=3.53, \mathrm{TLI}=.88, \mathrm{CFI}=.93, \mathrm{GFI}=.96, \mathrm{AGFI}=.91, \mathrm{RMSEA}=.07$. The internal consistency value of BWAS-T was calculated as .78 and it was concluded that reliability of the scale was acceptable. It was found that BWAS-T has positive associations with DUWAS-TR's total score and DUWAS-TR's sub-dimensions (i.e., working excessively and working compulsively), and thus the convergent validity was supported. As expected, BWAS-T was positively associated with job stress and weekly average working hours and negatively associated with job satisfaction and life satisfaction. In addition, BWAS-T and DUWAS-TR correlated with job stress, job satisfaction, life satisfaction and weekly average working hours with similar effect sizes. Based on these findings, BWAS-T is a measurement tool with evidence of psychometric properties.

Keywords: Workaholism, work addiction, Bergen work addiction scale, validity, reliability

\section{EXTENDED ABSTRACT}

There are a limited number of scales to measure workaholism. These are; the Work Addiction Risk Test (WART) developed by Robinson (1989), WorkBAT (The Workaholism Battery) developed by Spence and Robbins (1992), and DUWAS (The Dutch Work Addiction Scale) developed by Schaufeli, Taris, and Bakker (2006). These scales have been criticized in previous studies for reasons such as a lack of psychometric properties. Moreover, these scales do not really measure workaholism at the starting point (i.e., addiction) (Andreassen, Hetland, \& Pallesen, 2014). Andreassen, Griffiths, Hetland, and Pallesen (2012) developed BWAS (Bergen Work Addiction Scale) with a single factor that included seven items. Each item reflects a dimension of addiction (i.e., salience, mood modification, tolerance, withdrawal, conflict, relapse, and problems) (Griffiths, 1996; 2005; cited in Andreassen et al., 2012). BWAS was developed with a reduction of items in the existing work addiction scales and could be considered an important alternative tool to measure workaholism. Therefore, BWAS is expected to contribute to research carried out in Turkey related to workaholism. This study aimed to adapt BWAS into Turkish. The Turkish version of BWAS (BWAS-T) needs to meet several expectations (on factor structure, construct validity, and internal consistency) for testing its psychometric properties. In order to support the factor structure of the scale, CFA findings should be acceptable and like the study in which the scale was developed. In 
addition, convergent validity of BWAS-T should be supported. In order to test convergent validity, BWAS-T was expected to be positively associated with the Turkish version (DUWASTR) of the DUWAS (Duwas work addiction scale). Also BWAS-T was expected to be negatively related with job satisfaction (Andreassen, Hetland, Molde, \& Pallesen, 2011; Avanzi, van Dick, Fraccaroli, \& Sarchielli, 2012), life satisfaction (Andreassen et al., 2011; Aziz \& Zickar, 2006), job stress (Aziz, Wuensch, \& Brandon, 2010; Clark, Michel, Stevens, Howell, \& Scruggs, 2014; Shimazu \& Schaufeli, 2009), and positively related with average working hours to support its validity. Another important expectation was to be able to provide more support on the validity of BWAS-T, while the correlation coefficient of BWAS-T and DUWAS-TR with variables such as job stress, job satisfaction, life satisfaction and weekly average working hours was not expected to differ statistically. Finally, the internal consistency level of the scale was expected to be acceptable. Meeting this set of expectations will support the validity and reliability of BWAS-T.

\section{Method}

BWAS was translated into Turkish using a professional translation company, two linguists, and a researcher from the study. Then, the thinking-aloud-method (van Someron, Barnard, \& Sandberg, 1994) was applied. After that: a pilot study was conducted with 20 academicians. Finally, after some minor revisions, the Turkish version of the scale was created, and it was translated back into English by two linguists and the final version of BWAS-T was created. The data was collected with participation of 292 employees from various sectors operating in Sakarya. The relationship of BWAS-T with DUWAS-TR, work stress, job satisfaction, life satisfaction, and average working hours per week, was investigated for validity testing. In this context, the 14-item Turkish version (Dogan \& Tel, 2011) of DUWAS developed by Schaufeli et al. (2006) was used. Job satisfaction was assessed by the 5 -item version of the overall job satisfaction scale developed by Brayfield \& Rothe (1951). Job stress was assessed by a 7-item single factor job stress scale developed by House \& Rizzo (1972). Life satisfaction was measured by a single-item life satisfaction scale developed by Cheung \& Lucas (2014). Average working hours per week were measured with an open ended question.

\section{Results}

Total correlations of the items in BWAS-T were found between .48 and .53. The internal consistency value of BWAS-T was calculated as .78. CFA findings $\left(\chi^{2}=45.916, p<.001, \chi^{2}\right)$ $\mathrm{df}=3.53, \mathrm{TLI}=.88, \mathrm{CFI}=.93, \mathrm{GFI}=.96, \mathrm{AGFI}=.91, \mathrm{RMSEA}=.07$ ) and fit the data well for one factor solution. Factor loadings (in terms of standardized regression weights) ranged from .52 to .63 . The relationship between BWAS-T and DUWAS-TR was investigated in order to 
test the convergent validity of BWAS-T, and there was a moderately significant relationship between BWAS-T and DUWAS-TR which supports the convergent validity of BWAS-T. In addition, BWAS-T was positively correlated with job stress and negatively correlated with job satisfaction and life satisfaction. BWAS-T was found to be positively associated with weekly average working hours in parallel with previous empirical findings. Additionally, the correlation coefficients of DUWAS-TR and BWAS-T in relation to job stress, job satisfaction, life satisfaction, and weekly average working hours did not show statistically significant differences as calculated by the formula developed by Steiger (1980). In this respect, all findings supported the psychometric properties of BWAS-T.

\section{Discussion}

The findings of the factor structure of the scale were coherent with the original study so therefore a single-factor structure was confirmed. Findings related to the construct validity supported the construct validity of the scale. The finding of internal consistency was acceptable. Therefore, the findings of BWAS-T on the factor structure (CFA), reliability (Cronbach's Alpha), and construct validity provided evidence that support the psychometric properties of the BWAS-T. Thus, BWAS-T could be used in further research carried out in Turkey to measure workaholism. 
İşkoliklik kavramı 1970’lerde alkoliklikten yola çıkılarak ortaya atılmıştır ve aradan 50 yıl geçmesine rağmen kavramın tanımı konusunda henüz bir netlik sağlanamamıştır. Kavramı ilk olarak Oates (1971) kontrol edilemeyen kompulsif çalışma ihtiyacı düzeyinde işe bağımlılık olarak tanımlamıştır. Daha sonra kavrama, kişinin işini çok sevmesinden kaynaklı olarak işe güdülenmesi ve işten keyif alması gibi anlamlar yüklenmiştir (Machlowitz, 1980; Robinson, 1999). Schaufeli, Shimazu ve Taris (2009) kavramı aşırı ve kompulsif çalışma kapsamında incelemiştir. Andreassen, Griffiths, Hetland ve Pallesen (2012) ise kavramın bağımlılıkla ilişkisini incelemiştir. Araştırmacılar kavramı bireyin özel ilişkilerini, boş zaman aktivitelerini ve sağlığını olumsuz etkileyecek şekilde çalışmaya çok fazla enerji ve çaba sarf etmesi olarak tanımlamıştır. Buna bağlı olarak işkolikliği olumsuz sonuçlara yol açan bir iş bağımlılığı olarak değerlendirmiştir. Nitekim işkoliklik ile ilgili yapılan çalışmalarda işkolikliğin işe (örn., iş tatmini) ve yaşama yönelik (örn., yaşam tatmini) tutumları olumsuz etkilediği yönünde bulgular elde edilmiştir (Andreassen, Hetland, Molde ve Pallesen, 2011; Andreassen, Pallesen ve Torsheim, 2018; Clark, Michel, Stevens, Howell ve Scruggs, 2014; van Beek, Hu, Schaufeli, Taris ve Schreurs, 2012). Dolayısı ile her ne kadar kavram üzerinde net bir fikir birliği olmasa da işkolikliğin olumsuz bir özellik ya da davranışsal eğilim olduğu iddia edilebilir.

İşkoliklerin en belirgin özellikleri aşırı ve kompulsif çalışmalarıdır (Schaufeli, Taris ve Bakker, 2006). Ancak aşırı çalışma tek başına işkolikliğin bir göstergesi değildir. Çünkü dönemsel zorunluluklar, örgüt içindeki mesleki sorumluluklar ya da kişinin yaşamına ilişkin maddi sorumluluklarından ötürü bireyin aşırı derecede çalışması bazı durumlarda kaçınılmaz olabilmektedir (Schaufeli ve ark., 2009). İş bağımlılığında fazlaca çalışma, kişinin çalışmak zorunda olmadığı durumlarda bile, hatta bazen verim alamamasına rağmen çalışmaya devam etmesini ifade etmektedir (Shimazu, Schaufeli, Kamiyama ve Kawakami, 2015). Bu durum çoğu zaman kişinin sosyal ve aile yaşamını ihmal etmesine neden olmaktadır. Bu sebeple belirtilen aşırı çalışma; çalışkanlık, dönemsel ya da bağlamsal koşullar nedeniyle çok çalışma, işten keyif alarak coşku ve arzu ile verimli bir şekilde çalışmayı ifade eden çalışmaya tutkunluk (work engagement) ile karıştııılmamalıdır (Schaufeli, Taris ve van Rhenen, 2008). Kompulsif çalışma ise bireyin dürtüsel olarak çalışmayı sürdürmesini ifade etmektedir (Schaufeli ve ark., 2006). Bu eğilim kişinin özellikle tatillerde ya da boş zamanlarda bile sürekli işle ilgili zihnen ya da bedenen meşgul olmasına neden olmaktadır (Robinson, 1989). Bu özelliklere ek olarak işkolikler gerek olmadığı halde bile çalışmaya saplantılı bir şekilde devam etme, verimlilik 
düzeyi düşük olduğunda bile çalışmayı sürdürme ve ekonomik gerekçeler haricinde, güç, tanınma, beğenilme ve terfi alma gibi güdülerle çalışmayı yaşamın merkezinde tutma eğilimindedir (Andreassen, 2014; Clark ve ark., 2014; Shimazu ve Schaufeli, 2009; Srivastava, 2012; Sussman, 2012).

İşkoliklik özellikle 2000'li yıllardan sonra dünya genelinde yaygın bir şekilde çal1şılmaya başlanmıştır (Aziz ve Zickar, 2006; Clark, Michel, Zhdanova, Pui ve Baltes, 2016; Ng, Sorensen ve Feldman, 2007; Schaufeli ve ark., 2008). İşkolikliğe ilişkin yapılan çalışmalar temelde işkolikliğin ölçümüne (Robinson, 1989; Schaufeli, Bakker, van der Heijden ve Prins, 2009; Spence ve Robbins, 1992), nedenlerine (Bovornusvakool, Vodanovich, Ariyabuddhiphongs ve Sakkaphat, 2012), sonuçlarına (Scott, Moore ve Miceli, 1997), kavramsal ve teorik arka planını geliştirmeye yönelik yürütülmüş çalışmalardan (Andreassen, 2014; McMillan, O’Driscoll, Marsh ve Brady, 2001; Oates, 1971; Robinson, 1989) oluşmaktadır. İşkoliklik çalışmalarında temel problemlerden biri işkolikliğin ölçümüdür (Andreassen ve ark., 2012; Andreassen, Hetland ve Pallesen, 2014). İşkoliklik bazı araştırmacılarda pozitif (örn., Machlowitz, 1980) bazılarında ise negatif değerlendirildiği için (Schaufeli ve ark., 2009; Shimazu ve Schaufeli, 2009), kavramın ölçümünde farklı yaklaşımlar söz konusudur (Andreassen ve ark., 2012; Spence ve Robbins, 1992). Bu sebeple işkolikliğin ölçümüne ilişkin geliştirilmiş ölçeklerden elde edilen sonuçlar, işkolikliğin işle ve sosyal yaşamla ilişkili değişkenlere etkisi açısından birbirleri ile çelişmektedir (Avanzi ve ark., 2012; Aziz ve Zickar, 2006; Burke ve MacDermid, 1999; del Libano, Llorens, Salanova ve Schaufeli, 2012).

İşkolikliğin ölçümü için geliştirilen ölçek sayısı sınırlıdır. Bunlardan ilki Robinson (1989) tarafından geliştirilmiş Work Addiction Risk Test’tir (WART). WART, iş bağımlılığ konusunda sorun yaşayan bireylerdeki belirtilerden yola çıkarak geliştirilmiştir ve 25 maddeden oluşmaktadır. Ölçek aşırı çalışma, öz-değer, kontrol-mükemmeliyetçilik, yakınlık ve zihinsel meşguliyet olmak üzere beş faktörden oluşmaktadır (Robinson ve Post, 1994). Ayrıca ölçeğin 15 maddeli ya da tek faktörlü yapıları da alan yazında bulunmaktadır (Andreassen ve ark., 2012; Andreassen ve ark., 2014). Ancak ölçek, faktör yapısıyla ilgili tutarsiz bulgular (Andreassen, 2014; Flowers ve Robinson, 2002), kayg1 ve A tipi kişilik ile oldukça yüksek düzeyde ilişki göstermesi (Mudrack, 2006) gibi nedenlerden dolayı eleştirilmektedir (Quinones ve Griffiths, 2015). İşkolikliğin ölçümünde yaygın olarak kullanılan bir diğer ölçek Spence ve Robbins (1992) tarafından geliştirilmiş The Workaholism Battery'dir (WorkBAT). Ölçek 25 maddeden ve işe katılma, işe güdülenme 
ve işten zevk alma faktörlerinden oluşmaktadır. WorkBAT ilk olarak öğrenci örnekleminde uygulanmış ve ardından bazı maddeler çıkarılarak yetişkin örnekleminde 25 maddelik versiyonunun psikometrik özellikleri incelenmiştir. WorkBAT'ın psikometrik özellikleri bazı araştırmacılarca yetersiz bulunmuş (McMillan, Brady, O’Driscoll ve Marsh, 2002), özellikle işten keyif alma faktörü, işkolikliğin teorik arka planı ve kavramın çıkış noktasıyla uyuşmaması gibi nedenlerden dolayı (Mudrack, 2006; van Beek, Taris ve Schaufeli, 2011) eleştirilmiştir. WorkBAT ölçeğinin Türkçeye uyarlanmasında, Ersoy-Kart (2005) ölçekteki faktörlerden biri olan işe katılımın ölçekte yer almadığını görmüştür. Ölçek Türkiye'de bazı araştırmalarda kullanılmıştır (Akın ve Oğuz, 2010; Emhan, Mete ve Emhan, 2012). The Dutch Work Addiction Scale (DUWAS), işkolikliğin ölçümünde yaygın olarak kullanılan bir diğer ölçektir. DUWAS, WART ve WorkBAT ölçeklerindeki maddelerden de yararlanılarak, Hollanda ve Japonya örneklemlerinden elde edilen verilerle Schaufeli ve arkadaşları (2006) tarafindan geliştirilmiştir. Ölçeğin 17 ve 10 maddeli iki farklı formu bulunmaktadır. İşkolikliği aşırı çalışma ve kompulsif çalışma faktörleri ile ölçmektedir. Ölçeğin 17 maddeli formunun Türkçeye uyarlanması Doğan ve Tel (2011) tarafından yapılmış ve Duwas İşkoliklik Ölçeği’nin Türkçe formundan (DUWAS-TR) üç madde çıkarılmıştır. DUWAS, kompulsif eğilimleri ölçmede yetersiz kalması ve ölçeğin mevcut faktörlerinin işkolikliğin çıkış noktasını yansıtmadaki yetersizliği gibi nedenlerden dolayı eleştirilmektedir (Quinones ve Griffiths, 2015). İşkolikliğin ölçümünde yer alan az sayıda ölçeğin birbirleri ile uyumsuz olmaları, psikometrik özelliklerinin yetersizlikleri ve işkolikliğin teorik arka planını yeteri kadar yansıtmaması sebebiyle daha kapsamlı bir ölçek ihtiyacı dikkat çekmektedir (Andreassen ve ark., 2014).

Alan yazında her ne kadar bazı araştırmacılarca işkolikliğin esasen olumlu bir durum olduğu vurgulansa da (Machlowitz, 1980) mevcut ampirik bulgular işkolikliğin ağırlıklı olarak olumsuz sonuçlara yol açttğını göstermektedir (Clark ve ark., 2014; van Beek ve ark., 2012). Bu nedenle Andreassen ve arkadaşları (2012) işkolikliğin bir tür bağımlılık olan iş bağımlılığına dayandığını ve dolayısıyla bağımlılık kriterlerine uygun olarak geliştirilmiş bir ölçekle daha doğru bir şekilde ölçülebileceğini iddia etmişlerdir. Bu amaçla da Bergen Work Addiction Scale'i (BWAS) geliştirmişlerdir (Andreassen ve ark., 2012). Araştırmacılar, toplamda 12.137 katılımcının dahil olduğu iki ayrı örneklemden elde edilen veriler ile çalışmayı gerçekleştirmiştir. Başlangıçta bağımlılığı temsil eden 14 maddelik bir soru havuzu oluşturulmuştur. İlgili analizlerin ardından ise, her biri bağımlılığın bir faktörünü (belirginlik, tolerans, duygu durum düzenleme, nüks etme, yoksunluk, çatışma 
ve problem yaşama) temsil edecek şekilde ölçek yedi maddeye indirilmiştir (Griffiths, 1996; 2005; akt., Andreassen ve ark., 2012). Ölçek geliştirme çalışmasında tek faktörlü yapı doğrulanmış olup uyum indeksleri kabul edilebilir düzeyde tespit edilmiştir (tüm faktör yükleri > .49; RMSEA $=.077, \mathrm{CFI}=.96, \mathrm{TLI}=.95$ ). Ölçeğin yakınsak geçerliği diğer işkoliklik ölçekleri ile sınanmış ve ölçeğin geçerliğini destekleyici bulgular elde edilmiştir. Haftalık çalışma saati, liderlik pozisyonu ve öznel sağlık şikayetleri gibi değişkenler ile ilişkiler incelenerek ölçeğin ayırt edici geçerliği ortaya konmuştur. Ölçeğin içsel tutarlılık değerleri birinci örneklem için .84, ikinci örneklem için .80 olarak tespit edilmiştir. Sonuç olarak ölçeğin psikometrik özelliklerinin kabul edilebilir olduğu sonucuna varılmıştır.

İşkolikliğin ölçümüne ilişkin kısıtlılıkların azaltılması üzerine geliştirilen BWAS, kavramın ölçümünde önemli bir alternatif olmuştur. Öncelikle BWAS işkolikliğin çıkış noktasına (bağımlılığa) uygun kriterlerle geliştirilmiştir. Ancak işkolikliği ölçen diğer ölçeklerde oldukça sınırlı sayıda madde bağımlılık kriterlerine uygun bir içerik taşımaktadır. İkinci olarak BWAS, işkolikliğe ilişkin mevcut ampirik bulguların yoğunluğu ile uyuşan bir bakış açısı üzerine inşa edilmiştir. Mevcut ampirik bulguların çoğunda işkolikliğin işe ve sosyal yaşama yönelik tutum, davranış ve çıktıları olumsuz etkilediği görülmektedir. Bu kapsamda işkolikliğin; evlilik tatmini (Robinson, Flowers ve Ng 2006), iş-aile çatışması (Bakker, Demerouti ve Burke, 2009; del Libano, Llorens, Salanova ve Schaufeli, 2010), iş-yaşam dengesi (Aziz, Adkins, Walker, ve Wuensch, 2010), yaşam tatmini (Aziz ve Zickar, 2006), mutluluk (del Libano ve ark., 2010) gibi sosyal yaşama ilişkin değişkenleri olumsuz etkilediği tespit edilmiştir. Benzer şekilde işkolikliğin; stres (Aziz, Wuensch ve Brandon, 2010; Clark ve ark., 2014; Shimazu, Schaufeli ve Taris, 2010; Taris, Schaufeli ve Verhoeven, 2005), iş tatmini (Avanzi, van Dick, Fraccaroli ve Sarchielli, 2012; del Libano ve ark., 2010), tükenmişlik (Jenaabadi, Nejad, Abadi, Haghi ve Hojatinasab, 2016; Taris, Schaufeli ve Verhoeven, 2005; van Beek ve ark., 2012) ve performans (Shimazu ve Schaufeli, 2009) gibi iş yaşamına ilişkin değişkenleri olumsuz etkilediği tespit edilmiştir. Bu sebeple BWAS, WorkBAT ölçeğinde yer alan işe güdülenme, işten keyif alma gibi işkolikliğin kavramsal ve teorik arka planı ile uygun olmadığı iddia edilen faktörlerden ziyade, kavramın teorik arka planına daha uygun içerikle işkolikliği ölçmektedir. Çünkü işkolikliğe ilişkin mevcut ampirik çalışmaların çoğunun aksine WorkBAT ölçeğinde yer alan işe güdülenme ve işten keyif alma faktörlerinin iş tatmini (Avanzi ve ark.. 2012), yaşam tatmini (Andreassen ve ark., 201; Aziz ve Zickar, 2006) ve stres (Burke, 2000) değişkenleri olumsuz etkilemediği tespit edil- 
miştir. Ek olarak BWAS ölçeğinin psikometrik özellikleri farklı dillerdeki versiyonlarında da psikometrik özellikleri kabul edilebilir düzeyde tespit edilmiştir (Lehçe: Atroszko, Pallesen, Griffiths, ve Andreassen, 2017; İtalyanca: Molino, 2012; Macarca: Orosz ve ark., 2016). Yukarıda vurgulanan tüm bu hususlardan dolayı BWAS'ın işkolikliğin ölçümünde önemli bir alternatif olduğu düşünülmektedir.

BWAS'ın işkoliklik kavramını açıklama ve ölçmeye katkıları sebebiyle bu çalışmada BWAS'ın Türkçe uyarlanması gerçekleştirilecektir. BWAS'ın Türkçeye uyarlanması ve Türkçe formunun (BWAS-T) geçerliğinin ve güvenirliğinin test edilmesi için bir takım beklentileri karşılaması gerekmektedir. Bunlardan ilki faktör yapısının belirlenmesidir. BWAS, geliştirildiği çalışmada tek faktörlü bir yapı olarak ortaya atılmış ve uyum indeksleri kabul edilebilir düzeyde tespit edilmiştir. Bu çalışmada da ölçeğin tek faktörlü yapısının desteklenmesi ve Doğrulayıcı Faktör Analizi (DFA) sonucunda uyum indekslerinin kabul edilebilir düzeyde olması beklenmektedir. Ölçeğin geçerliğinin test edilmesi için kullanılan ikinci yöntem ise yine yapı geçerliği kapsamında değerlendirilen yakınsak geçerliğin sınanması olacaktır. Bunun için ölçeğin, halihazırda Türkçeye uyarlanmış olan bir başka işkoliklik ölçeği olan DUWAS-TR ile ilişkisi incelenecek ve aralarında anlamlı bir ilişki olması beklenecektir. Yapı geçerliği kapsamında yapılan son analizde ise ölçeğin teorik olarak ilişkili diğer yapılarla (iş stresi, iş tatmini, yaşam tatmini ve haftalık ortalama çalışma saati) ilişkisinin incelenmesi olmuştur. İşkoliklik ile iş stresi arasındaki ilişkiyi inceleyen çalışmalarda bu kavramların çoğunlukla pozitif ilişki gösterdiği belirtilmiştir (Aziz, Wuensch ve Brandon, 2010; Clark ve ark., 2014; Kanai, Wakabayashi ve Fling, 1996; Shimazu ve Schaufeli, 2009; Shimazu ve ark., 2010; Taris ve ark., 2005). Bu nedenle, BWAS-T ve iş stresi arasında pozitif bir ilişki elde edilmesi beklenmiştir. Daha önce yapılan çalışmalarda işkoliklikle iş tatmini (Andreassen ve ark., 2011; Avanzi ve ark., 2012; Aziz ve Zickar, 2006; del Libano ve ark., 2012; Schaufeli ve ark., 2009; Shimazu ve Schaufeli, 2009) ve yaşam tatmini (Andreassen ve ark., 2011; Aziz ve Zickar, 2006) arasında ağırlıklı olarak negatif ilişki tespit edilmiştir. Bu sebeple BWAS-T’nin iş tatmini ve yaşam tatmini ile negatif ilişkili olması beklenmiştir. Aşırı çalışma işkolikliğin önemli bir belirtisi olduğu için (Schaufeli ve ark., 2006) BWAS-T ve haftalık ortalama çalışma saati arasında pozitif ilişki elde edilmesi beklenmiştir. Ayrıca BWAS-T ile DUWAS-TR'nin iş stresi, iş tatmini, yaşam tatmini ve haftalık ortalama çalışma saati gibi değişkenlerle ilişkisine ilişkin korelasyon katsayısının istatistiki açıdan farklılaşmaması ölçeğin geçerliğini destekleyici yönde olacaktır. Son olarak ölçeğin içsel tutarlılık 
düzeyinin kabul edilebilir düzeyde olması beklenmiştir. Söz konusu beklentilerin karşılanması ölçeğin geçerliğini ve güvenirliğini destekleyecektir.

\section{YÖNTEM}

\section{Katılımcılar}

Araştırmaya Sakarya’da kamu ve özel sektör örgütlerinden, eğitim, sağlık, doğalgaz, gıda, otomotiv gibi alanlarda faaliyet gösteren tamamı büyük ölçekli toplam dokuz ayrı örgütün çalışanları katılmıştır. Katılımcıların \%54.1'i erkek, \% 56.8'i evli, \% 61'i kamu sektörü çalışanı, yaş ortalaması $34.16(S S=9.02)$ ve ortalama aylık geliri $3717.13(S S=$ 1687.09) Türk Lirasıdır. Katılımcıların \%28.1'i lise ve öncesi, \% 10.3’ü ön lisans, \% 36.6'sı lisans, \% 11.3'ü yüksek lisans ve \%11.3'ü doktora mezunudur.

\section{Veri Toplama Araçları}

Araştırmada veri toplama aracı olarak anket tekniğinden yararlanılmıştır. Anketin birinci bölümünde araştırma kapsamında Türkçeye uyarlanan Bergen İş Bağımlılığı Ölçeği bulunmaktadır. Anketin ikinci bölümünde House ve Rizzo (1972) tarafından geliştirilmiş İş Stresi Ölçeği, Brayfield ve Rothe (1951) tarafından geliştirilmiş Genel İş Tatmini Ölçeği ve Cheung ve Lucas (2014) tarafindan geliştirilmiş Yaşam Tatmini Ölçeği yer almaktadır. Anketin üçüncü bölümünde Schaufeli ve arkadaşları (2006) tarafından geliştirilmiş DUWAS işkoliklik ölçeği kullanılmıştır. Son bölümde ise katılımcıların, yaş, medeni durum, cinsiyet ve eğitim durumu gibi demografik özelliklerine ilişkin sorular yer almıştır. Ayrıca katılımcıların haftalık ortalama çalışma saatini ölçen soru da son bölümde yer almıştır. Katılımcıların haftalık ortalama çalışma saatini belirlemek için "haftada ortalama çalışma süreniz kaç saattir?” şeklinde açık uçlu bir soru sorulmuştur.

Bergen İş Bağımlılığı Ölçeği (BWAS): Andreasson ve arkadaşları (2012) tarafından bağımlılık kriterlerinden yola çıkarak geliştirilmiştir. Ölçek başlangıçta 14 madde olarak tasarlanmış, analizlerden sonra yedi maddeye indirilmiştir ve tek faktörlü yapıdan oluşmaktadır. Ölçek 1 = Hiçbir Zaman, 2 = Nadiren, 3 = Bazen, $4=$ Sıklıkla, $5=$ Her Zaman yanıt kategorisinde 5'li Likert tipi ile değerlendirilmiştir. Ölçekte yer alan örnek bir madde "Geçtiğimiz yıl boyunca ne sıklıkla suçluluk, kaygl, çaresizlik ve depresyon duygularını azaltmak için çalıştınız?” şeklindedir.

Ölçeğin Türkçeye çevirilme sürecinden önce ilk olarak ölçeği geliştiren yazarlarla iletişime geçilmiş ve ölçeğin Türkçeye uyarlanmasına ilişkin izin alınmıştır. Ölçeğin çeviri 
işlemlerine ilişkin süreç izlenirken Sousa ve Rojjanasrirat'ın (2011) öneriler seti dikkate alınmıştır. Bu doğrultuda ölçek bir profesyonel çeviri firması, iki İngiliz Dili ve Edebiyatı öğretim elemanı ve araştırmacının kendisi tarafından Türkçeye çevirilmiştir. Söz konusu çeviriler üç kişiden oluşan alan uzmanları tarafindan incelenerek ve her bir madde için en uygun ifadelerden yararlanılarak tek bir çeviri altında toplanmıştır. Daha sonra sesli düşünme tekniği (thinking-aloud-method) (van Someron, Barnard ve Sandberg, 1994) ile bir grup doktora öğrencisine ölçekteki maddelerden ne anladığı sorulmuştur ve sonrasında ölçekte küçük birkaç revizyon yapılmıştır. Çeviriler pilot uygulama kapsamında 20 akademisyene ulaştırılmış ve soruların anlaşılırlığı ve Türk dili ve kültürüne uygunluğu açısından geri bildirimler alınmıştır. Son olarak küçük revizyonlardan sonra ölçeğin Türkçe formuna son hal verilmiş ve daha önce ölçeğin orijinalini bilmeyen iki dil bilimci tarafindan İngilizceye geri çevirme işlemi (back translation) yapılmıştır. Birkaç fiil ve isimde farklı kavramlar kullanımı haricinde ölçeğin orijinal formundan farklılaşan bir görüntü ortaya çıkmamıştır. Dolayısı ile ölçeğin Türkçe formuna (BWAS-T) son hal verilmiştir.

Duwas İşkoliklik Ölçeği (DUWAS-TR). Bu ölçek Schaufeli ve arkadaşları (2006) tarafından geliştirilmiştir ve 17 maddeden oluşmaktadır. Ölçeğin aşırı çalışma ve kompulsif çalışma olmak üzere iki faktörü mevcuttur. Schaufeli ve arkadaşları (2006) ölçeğin psikometrik özelliklerinin kabul edilebilir düzeyde ve içsel tutarlılık katsayılarını aşırı çalışma faktörü için .80 ve kompulsif çalışma faktörü için .86 olarak tespit etmiştir. Ölçeğin Türkçeye uyarlaması Doğan ve Tel (2011) tarafından yapılmış ve 17 maddelik DUWAS ölçeğinin uyarlama çalışmasında ölçekten üç madde çıkarılmış ve ölçek 14 maddeye indirilmiştir. Ölçeğin Türkçe versiyonu (DUWAS-TR) işkolikliği 14 madde ve iki faktör (aşırı çalışma için sekiz madde ve kompulsif çalışma için altı madde) ile ölçmektedir. Uyarlama çalışmasında ölçeğin güvenirlik katsayılarının aşırı çalışma için .76, kompulsif çalışma için .74 olduğu bildirilmiştir. DUWAS-TR birçok araştırmacı (Akçakanat, Muhammet ve Demirgil, 2017; Bulgurcu Gürel ve Altunoğlu, 2016; Özsoy, 2018) tarafından da kullanılmıştır ve içsel tutarlılık değerleri, her bir faktör için .70 ve üzerinde tespit edilmiştir. Ölçek 5'li Likert (1 = Hiç Uygun Değil, 2 = Uygun Değil, 3 = Biraz Uygun, 4 = Uygun, 5 = Tamamen Uygun) tipi yantt kategorisine sahiptir.

Genel İş Tatmini Ölçeği. Bu çalışmada Brayfield ve Rothe (1951) tarafindan geliştirilmiş tek faktörlü Genel İş Tatmini Ölçeğinin 5 maddelik versiyonu kullanılmıştır. Ölçeğin içsel tutarlılık değerinin yüksek $(\alpha=.87)$, psikometrik özelliklerinin de kabul edilebilir aralıkta olduğunu tespit etmiştir (Brayfield ve Rothe, 1951). Ölçeğin Türkçeye 
çeviri çalışması Bilgin (1995) tarafından yapılmıştır. Ölçek birçok araştırmacı tarafından (Doğan ve Aslan, 2018; Özsoy ve Ardıç, 2017; Yürür ve Keser, 2011) daha önceden kullanılmıştır. Özsoy ve Ardıç, (2017) yaptıkları faktör analizinde ölçeğin tek faktörlü yapısının desteklendiğini ve içsel tutarlılık değerini .84 tespit etmiştir. Ölçek 5'li Likert ( 1 = Kesinlikle Katılmiyorum, 2 = Katılmıyorum, 3 = Kararsızım, 4 = Katılıorum, 5 = Kesinlikle Katılıyorum) tipi ile değerlendirilmektedir.

İş Stresi Ölçeği. House ve Rizzo (1972) tarafından geliştirilmiş 7 madde ve tek bir faktörden oluşan iş stresi ölçeği kullanılmıştır. House ve Rizzo (1972) ölçeğin psikometrik özelliklerinin kabul edilebilir aralıkta ve güvenirlik katsayısının .83 olduğunu tespit etmiştir. Ölçeğin Türk kültürüne uyarlaması Efeoğlu (2006) tarafından yapılmış ve ölçeğin Türkçe versiyonunun geçerli ve güvenilir olduğu sonucuna varılmıştır. Uyarlama çalışmasında ölçeğin içsel tutarlık değeri .84 olarak hesaplanmış, ölçeğin kullanıldığı diğer çalışmalarda (Bulgurcu Gürel ve Altunoğlu, 2016; Yeşiltaş ve Ekici, 2017) içsel tutarlık değerlerine ilişkin benzer bulgular elde edilmiş ve tek faktörlü yapısı desteklenmiştir (Yıldırım, 2008). Ölçek 1 = Hiçbir Zaman, 2 = Nadiren, 3 = Bazen, 4 = Sıklıkla, 5 = Her Zaman şeklinde derecelendirilmiş 5'li Likert tipindedir.

Yaşam Tatmini Ölçeği. Cheung ve Lucas (2014) tarafından geliştirilmiş tek maddeli yaşam tatmini ölçeği kullanılmıştır. Cheung ve Lucas (2014) ölçeğin uzun formlu yaşam tatmini ölçekleri ile yakınsak geçerliğini sınamış ve ölçeğin psikometrik özelliklerinin kabul edilebilir olduğu sonucuna varmıştır. Ölçek araştırmacı tarafından Türkçeye çevirilmiş ve 5'li Likert tipi ( 1 = Hiç Memnun Değilim, 2 = Memnun Değilim, 3 = Kısmen Memnunum, 4 = Memnunum, 5 = Çok Memnunum) tipi yanıt kategorisine sahiptir

\section{İşlem}

Araştırmadaki veriler Sakarya'da faaliyet gösteren çeşitli sektörlerdeki kurumların çalışanlarının katılımı ile toplanmıştır. Veriler Şubat 2018-Mart 2018 tarihleri arasında toplanmıştır. Kamu kurumlarındaki yöneticilerin bilgileri dahilinde anket formları araştırmacının kendisi tarafından katılımcılara elden dağıtılmıştır. Özel sektör örgütlerine ise yöneticilerin bilgisi dahilinde anket formları yöneticilere çalışanlara dağıltılmak üzere teslim edilmiştir. Katılımcılara iki hafta sonra anket formlarının teslim alınacağı ve katılımın gönüllülük esasına dayalı olduğu bilgisi verilmiştir. Bu kapsamda yaklaşık 400 anket formu dağıtılmıştır. Eksik ve özensiz anket formları çıkarıldıktan sonra (yaklaşık \% 7), toplamda 292 adet (geri dönüş oranı \% 73) geçerli anket formu elde edilmiş 
ve ilgili analizlere tabi tutulmuştur. DFA için örneklem sayısının 200'den ve ölçekteki madde sayısının 10 katından fazla olması gerektiği için (Myers, Ahn ve Jin, 2011) söz konusu örneklem büyüklüğünün araştırma kapsamında ihtiyaç duyulacak istatistiki analizler için yeterli olacağı tespit edilmiştir. Verilerin analizinde madde analizi, iç tutarlılık analizi için Cronbach Alpha değeri, DFA için yapısal eşitlik modellemesi, yapılar arasındaki ilişkiyi incelemek ve yakınsak geçerliği sınamak için korelasyon analizi ve BWAS-T ve DUWAS-TR'nin diğer yapılarla ilişkisindeki farklılı̆̆ testi uygulanmıştır. Verilerinin analizleri için SPSS for Windows 21.0 ve AMOS 22.0 (IBM, 2018) paket programlarından yararlanılmıştır.

\section{BULGULAR}

Madde Analizi. Ölçekteki maddelere ilişkin madde toplam korelasyonları .48 ile .53 arasında tespit edilmiştir. Ayrıca ölçekten madde çıkartılması durumunda ölçeğin içsel tutarlılık düzeyinin artmayacağı tespit edilmiştir.

Doğrulayıcı Faktör Analizi. Ölçeğin orijinalinde olduğu gibi bu çalışmada da tek faktörlü yapı doğrulanmıştır. DFA bulguları, $\chi 2=45.916, p<.001, \chi 2 / \mathrm{df}=3.53$, TLI (Tucker-Lewis Index $)=.88$, CFI $($ Comparative Fit Index $)=.93$, GFI (Goodness of Fit Index) $=.96, \mathrm{AGFI}$ (Adjusted Goodness of Fit Index) =.91, RMSEA (Root Mean Square Error of Approximation $)=.07$ şeklindedir. BWAS-T için faktör yükleri .52 ile .63 arasındadır.

Tanımlayıcı İstatistikler ve Güvenirlik Bulguları. Araştırma kapsamında yer alan değişkenlere ilişkin tanımlayıcı istatistikler ve içsel tutarlılık değerlerinin belirlenmesi için tanımlayıcı istatistikler ve içsel tutarlılık değerleri hesaplanmıştır. Bu bulgular Tablo 1 'de sunulmuştur.

Tablo 1. Tanımlayıcı istatistikler, içsel tutarlılık ve korelasyon analizi bulguları

\begin{tabular}{|c|c|c|c|c|c|c|c|c|c|}
\hline & $\boldsymbol{O}$ & $S S$ & 1 & 2 & 3 & 4 & 5 & 6 & 7 \\
\hline 1.BWAS-T & 2.38 & .59 & $(.78)$ & & & & & & \\
\hline 2.DUWAS-TR & 3.17 & .63 & $.47 * * *$ & $(.85)$ & & & & & \\
\hline 3.Aşırı Çalışma & 3.09 & .71 & $.56^{* * *}$ & $.78 * * *$ & $(.78)$ & & & & \\
\hline 4.Kompulsif Çalışma & 3.23 & .80 & $.43 * * *$ & $.78 * * *$ & $.60 * * *$ & $(.78)$ & & & \\
\hline 5.İ̧̧ Stresi & 3.42 & .89 & $.30 * * *$ & $.32 * * *$ & $.28 * * *$ & $.27 * * *$ & $(.81)$ & & \\
\hline 6.İş Tatmini & 2.68 & .86 & $-.14 *$ & $-.15 * *$ & $-.23 * * *$ & $-.21 * * *$ & $-.27 * * *$ & $(.78)$ & \\
\hline 7.Yaşam Tatmini & 3.69 & 1.09 & $-.13 *$ & $-.15 * *$ & $-.21 * * *$ & $-.11 *$ & $-.24 * * *$ & $.55 * * *$ & - \\
\hline 8.Haftalık Çalışma Saati & 44.11 & 12.31 & $.29 * * *$ & $.36^{* *}$ & $.31 * * *$ & $.31 * * *$ & $.18^{* *}$ & $-.13 *$ & $-.16^{*}$ \\
\hline
\end{tabular}

Not. $* p<.05, * * p<.01,{ }^{* * *} p<.001 . O=$ Ortalama, SS = Standart Sapma, Parantez içindeki değerler Cronbach Alpha güvenirlik katsayllartnı ifade etmektedir. 
Tablo 1'de görüldüğü üzere BWAS-T'nin içsel tutarlılık değeri .78 olarak hesaplanmıştır. Bu bulgu ölçeğin güvenirliğinin kabul edilebilir düzeyde olduğunu göstermektedir. Araştırma kapsamında kullanılan diğer ölçeklere ilişkin içsel tutarlılık katsayıları da ölçeklerin güvenirliğini destekler niteliktedir (minimum $\alpha$ değeri = .78). Katılımcıların işkoliklik düzeyi, düşük (BWAS-T) ve orta düzey (DUWAS) arasında değişkenlik göstermiştir. Katılımcıların iş stresi ve yaşam tatmini düzeyi orta seviyede, iş tatminleri düşük seviyede belirlenmiştir ve haftalık ortalama çalışma süresi 44.11 saat olarak tespit edilmiştir.

Yakınsak Geçerlik. Yapı geçerliğini test etmek için uygulanan korelasyon analizi bulguları Tablo 1'de sunulmuştur. Buna göre yakınsak geçerliğin test edilmesi için BWAS-T ile DUWAS-TR arasındaki ilişki incelenmiştir. BWAS-T ile DUWAS-TR'nin toplam skoru arasındaki korelasyon katsayısı $.47(\mathrm{p}<0.001)$ olarak hesaplanmıştır. Yani daha önceden Türk kültürüne uyarlanmış, geçerliği ve güvenirliği test edilmiş DUWASTR ile BWAS-T arasında orta düzeyde anlamlı ilişki elde edilmiştir. Bu bulgu BWAST'nin yakınsak geçerliğini desteklemektedir. Ek olarak DUWAS-TR'nin alt faktörleri olan aşırı ve kompulsif çalışma ile BWAS-T arasında yine benzer şekilde orta kuvvette ve pozitif yönlü anlamlı ilişkiler elde edilmiştir.

Yapılar Arasındaki İlişki. BWAS-T’nin geçerliğini test etmek için ek olarak ölçeğin teorik açıdan ilişkili olduğu diğer yapılarla olan korelasyonları incelenmiştir. Tablo 1 'de sunulan bu sonuçlar, BWAS-T ile iş stresi ve haftalık çalışma saati arasında pozitif; iş tatmini ve yaşam tatmini arasında ise negatif yönde anlamlı ilişkilerin olduğunu göstermektedir. Ayrıca BWAS-T ve DUWAS-TR'nin bu yapılarla olan ilişkilerinin anlamlı olarak farklılaşıp farklılaşmadı̆̆ 1 da Steiger'ın (1980) geliştirdiği formülle hesaplanan z testi ile incelenmiştir. DUWAS-TR ve BWAS-T'nin iş stresi $(z=-.35, p>.05)$, iş tatmini $(z=-.17, p>.05)$, yaşam tatmini $(z=.33, p>.05)$ ve haftalık ortalama çalışma saati $(z=-1.24, p>.05)$ ile ilişkisinde elde edilen korelasyon katsayıları istatistiki açıdan anlamlı farklılıklar göstermemiştir. Bu bulgu da BWAS-T'nin DUWAS-TR ile benzer psikometrik özellikler gösterdiğini desteklemektedir.

\section{TARTIŞMA}

Araştırma kapsamında elde edilen bulgular genel olarak değerlendirildiğinde BWAST'nin psikometrik özelliklerini destekleyici bulgular elde edilmiştir. BWAS-T'nin maddelerine ilişkin uygulanan madde analizinde, toplam madde korelasyonlarının kabul edi- 
lebilir aralıkta olduğu ve ölçekten madde çıarılması durumunda ölçeğin güvenilirliğinin artmadığı görülmüştür. Bu sebeple ölçekten madde çıkarılmamıştır. Ölçeğin faktör yap1sına ilişkin elde edilen bulgular orjinal çalışmanın bulgularıyla oldukça yakındır (Andreassen ve ark., 2012) ve genel olarak uyum indeksleri kabul edilebilir aralıktadır (Schermelleh-Engel, Moosbrugger ve Müler, 2003). BWAS-T’nin içsel tutarlılık katsayısı kabul edilebilir bulunmuştur. Bu bulgu ölçeğin geliştirildiği çalışmada (Andreassen ve ark., 2012) ve ölçeğin kullanıldığı diğer çalışmalarda (Molino, Bakker ve Ghislieri, 2016; Orosz ve ark., 2016) elde edilen içsel tutarlılık bulguları ile uyumludur.

Yakınsak geçerliğe ilişkin elde edilen bulgular incelendiğinde BWAS-T ve DUWASTR arasında orta düzeyde ilişki olduğu tespit edilmiştir. Bu bulgu ölçeğin yakınsak geçerliğini desteklemektedir. BWAS-T'nin diğer yapılarla ilişkisi incelendiğinde genel olarak geçerlik beklentilerini destekleyici bulgular elde edilmiştir. İşkoliklik ve iş stresi arasındaki ilişkinin ağırlıklı olarak pozitif yönde olduğu görülmektedir (Avanzi ve ark., 2012; Aziz ve Zickar, 2006; del Libano ve ark., 2012; Kanai ve ark., 1996; Schaufeli ve ark., 2009; Shimazu ve Schaufeli, 2009). Araştırmada BWAS-T ve iş stresi arasında pozitif yönde ilişki tespit edilmiştir. Bu bulgu da BWAS-T'nin geçerliğini destekleyici bir bulgudur. İşkoliklikle işe ve sosyal yaşama yönelik tutumlar arasındaki ilişkiyi inceleyen çalışmalarda işkolikliğin ağırlıklı olarak iş ve sosyal yaşama yönelik değişkenlerle ters yönde ilişkili olduğu bulgulanmıştır (Clark ve ark., 2014; Robinson, Flowers ve Ng, 2006; Shimazu ve Schaufeli, 2009; van Beek ve ark., 2012). Daha önceki çalışmalarda işkoliklik ve iş tatmini (Andreassen ve ark., 2011; Avanzi ve ark., 2012; Aziz ve Zickar, 2006; del Libano ve ark., 2012; Schaufeli ve ark., 2009; Shimazu ve Schaufeli, 2009) ve yaşam tatmini (Andreassen ve ark., 2011; Aziz ve Zickar, 2006) arasında ağırlıklı olarak negatif ilişkiler elde edilmiştir. Bu çalışmada da daha önceki çalışmalara benzer şekilde BWAS-T ile iş tatmini ve yaşam tatmini arasında negatif yönde bir ilişki ortaya çıkmıştır. Bu bulgular da ölçeğin geçerliğini desteklemektedir. Beklenildiği üzere BWAS-T ve haftalık ortalama çalışma saati arasında pozitif bir ilişki saptanmıştır. Bu bulgu hem ölçeğin geliştirildiği çalışma hem de konuya ilişkin temel çalışmalarda vurgulanan aşırı çalışma ve işkoliklik arasındaki ilişkiyi (Andreasson ve ark., 2012; Schaufeli ve ark., 2009) destekler niteliktedir. Bu bakımdan haftalık ortalama çalışma saati ve BWAS-T arasında elde edilen pozitif ilişki ölçeğin geçerliğini destekler niteliktedir.

DUWAS-TR ve BWAS-T iş stresi, iş tatmini, yaşam tatmini ve haftalık ortalama çalışma saati gibi değişkenlerle benzer etki büyüklüğü ve yönünde (iş stresi ve haftalık 
ortalama çalışma saati ile pozitif, iş ve yaşam tatmini ile negatif) ilişki sergilemiştir. BWAS-T ve DUWAS-TR'nin iş stresi, iş tatmini, yaşam tatmini ve haftalık ortalama çalışma saati ile ilişkilerindeki etki büyüklüğünde istatistiki açıdan anlamlı farklılıkların olup olmadığını tespit etmek için uygulanan $\mathrm{z}$ testinde, her iki ölçeğin de söz konusu değişkenlerle birbirleri ile istatistiki açıdan farklılık göstermeyecek düzeyde ilişkili olduğu bulgulanmıştır. Bu bulgu BWAS-T’nin yakınsak geçerliğini destekler niteliktedir. Her ne kadar kompulsif eğilimleri ölçme amacıyla ölçekte yer alan yetersiz madde sayıs1 ve ölçeğin mevcut faktörlerinin işkolikliğin teorik arka planını yansıtmadaki yetersizliği gibi nedenlerden dolayı DUWAS eleştirilse (Quinones ve Griffiths, 2015) de, ulusal (Doğan ve Tel, 2011; Özsoy, 2018) ve uluslararası (Schaufeli ve ark., 2009; Shimazu ve Schaufeli, 2009) alanda yapılan çalışmalar DUWAS'ın WorkBAT ve WART'a göre psikometrik özelliklerinin daha iyi olduğuna işaret etmektedir. Bu sebeple BWAS-T ve DUWAS-TR'nin iş stresi, iş tatmini, yaşam tatmini ve haftalık ortalama çalışma saati ile ilişkisinin benzer etki büyüklüğünde olması BWAS-T'nin yakınsak geçerliğine ek bulgu sunmaktadir.

BWAS işkolikliğin ölçümüne alternatif oluşturması açısından önemlidir. Bu bakımdan BWAS-T'nin, Türkiye örnekleminde işkoliklikle ilgili yürütülecek çalışmaların sayısını ve niteliğini artıracağı düşünülmektedir. Bununla birlikte bu araştırma belirli s1nırlılıkları da içermektedir. Araştırmanın en temel sınırlılığı katılımcı sayısının sınırlı olması ve bu sebeple örneklemin hetorojenlik düzeyinin düşük olmasıdır. Ayrıca test-tekrar test yöntemiyle ölçeğin güvenirliğinin sınanmaması bir diğer sınırlılıktır.

Sonuç olarak bu çalışmada BWAS-T'nin psikometrik özellikleri (faktör yapısı, yapı geçerliği, güvenirliği) incelenmiş ve ölçeğin psikometrik özelliklerine yönelik çeşitli kanıtlar elde edilmiştir. Dolayısı ile BWAS-T’nin Türkiye örnekleminde işkoliklikle ilgili yürütülecek gelecek araştırmalarda kullanılabileceği düşünülmektedir.

Hakem Değerlendirmesi: Dış bağımsız.

Çıkar Çatışması: Yazar çıkar çatışması bildirmemiştir.

Finansal Destek: Yazar bu çalışma için finansal destek almadığını beyan etmiştir.

Peer-review: Externally peer-reviewed.

Conflict of Interest: The author has no conflict of interest to declare.

Grant Support: The author declared that this study has received no financial support. 


\section{Kaynakça/References}

Akçakanat, T., Muhammet, M., ve Demirgil, Z. (2017). İşkolikliğin kuşaklara göre karşılaştırılması: Süleyman Demirel Üniversitesi akademisyenleri üzerine bir araştırma. MANAS Sosyal Araştırmalar Dergisi, 6(3), 135-155.

Akın, U. ve Oğuz, E. (2010). Öğretmenlerin işkoliklik ve tükenmişlik düzeylerinin ilişkisi ve çeşitli değişkenler açısından incelenmesi. Kuram ve Uygulamada Eğitim Yönetimi, 16(3) 309-327.

Andreassen, C. S. (2014). Workaholism: An overview and current status of research. Journal of Behavioral Addictions, 3(1), 1-11. doi:10.1556/JBA.2.2013.017

Andreassen, C. S., Griffiths, M. D., Hetland, J. ve Pallesen, S. (2012). Development of a work addiction scale. Scandinavian Journal of Psychology, 53(3), 265-72. doi:10.1111/j.1467-9450.2012.00947.x

Andreassen, C. S., Hetland, J., Molde, H. ve Pallesen, S. (2011). "Workaholism" and potential outcomes in wellbeing and health in a cross-occupational sample. Stress and Health, 27(3), 209214. doi:10.1002/smi.1366

Andreassen, C, S., Hetland, J. ve Pallesen, S. (2014). Psychometric assessment of workaholism measures. Journal of Managerial Psychology, 29(1), 7-24. doi:10.1108/JMP-05-2013-0143

Andreassen C. S., Pallesen S., ve Torsheim T. (2018). Workaholism as a mediator between work-related stressors and health outcomes.International Journal of Environmental Research and Public Health, 15(1), 73. doi:10.3390/ijerph15010073

Atroszko, P. A., Pallesen, S., Griffiths, M. D. ve Andreassen, C. S. (2017). Work addiction in Poland: Adaptation of the Bergen Work Addiction Scale and relationship with psychopathology. Health Psychology Report, 5(4), 345-355. doi:10.5114/hpr.2017.68759

Avanzi, L., van Dick, R., Fraccaroli, F. ve Sarchielli, G. (2012). The downside of organizational identification: Relations between identification, workaholism and well-being. Work and Stress, 26(3), 289-307. doi:10.1080/02678373.2012.712291

Aziz, S., Adkins, C. T., Walker, A. G., ve Wuensch, K. L. (2010). Workaholism and work-life imbalance: Does cultural origin influence the relationship? International Journal of Psychology, 41(1), 72-79. doi: 10.1080/00207590902913442

Aziz, S., Wuensch, K. L. ve Brandon, H. R. (2010). A comparison among worker types using a composites approach and median splits. Psychological Record, 60(4), 627-642. doi:10.1007/BF03395736

Aziz, S. ve Zickar, M. J. (2006). A cluster analysis investigation of workaholism as a syndrome. Journal of Occupational Health Psychology, 11(1), 52-62. doi:10.1037/1076-8998.11.1.52

Bilgin, N. (1995). Sosyal Psikolojiye Giriş. 3. Basım. İzmir Kitaplı̆̆ı: İzmir.

Bovornusvakool, W., Vodanovich, S. J., Ariyabuddhiphongs, C. ve Sakkaphat, N. (2012). Examining the antecedents and consequences of workaholism. The Psychologist-Manager Journal, 15(1), 56-70. doi:10.1080/10887156.2012.649994

Bakker, A. B., Demerouti, E., ve Burke, R. (2009). Workaholism and relationship quality: A spillovercrossover perspective. Journal of Occupational Health Psychology, 14(1) 23-33. doi: 10.1037/ a0013290.Brayfield, A. H. ve Rothe, H. F. (1951). An index of job satisfaction. Journal of Applied Psychology, 35(5), 307-311. doi:10.1037/h0055617

Burke, R. J. (2000). Workaholism in organizations: Psychological and physical well-being consequences. Stress Medicine, 16(1)11-16. doi: 10.1002/(SICI)1099-1700(200001)16:1<11::AID-SMI825>3.0.CO;2-U

Bulgurcu Gürel, E. B. ve Altunoğlu, A. E. (2016). İşkoliklik, iş stresi ve yaşam doyumu arasındaki ilişkilerin incelenmesi: Muğla ilinde bir araştırma. Journal of International Social Research, 9(42), 1431-1438. doi:10.33206/mjss.460701 
Burke, R. J. ve MacDermid, G. (1999). Are workaholics job satisfied and successful in their careers? Career Development International, 4(5), 277-282. doi:10.1108/13620439910279761

Cheung, F. ve Lucas, R. E. (2014). Assessing the validity of single-item life satisfaction measures: Results from three large samples. Quality of Life Research, 23(10), 2809-2818. doi:10.1007/ s11136-014-0726-4

Clark, M. A., Michel, J. S., Stevens, G. W., Howell, J. W. ve Scruggs, R. S. (2014). Workaholism, work engagement, and work-family outcomes: Exploring the mediating role of positive and negative emotion traits. Stress and Health, 30(4), 287-300. doi:10.1002/smi.2511

Clark, M. A., Michel, J. S., Zhdanova, L., Pui, S. ve Baltes, B. B. (2016). All work and no play? A metaanalytic examination of the correlates and outcomes of workaholism. Journal of Management, 42(7), 1836-1873. doi:10.1177/0149206314522301

del Libano, M., Llorens, S., Salanova, M. ve Schaufeli, W. B. (2010). Validity of a brief workaholism scale. Psicothema, 22(1)143-150.

del Libano, M., Llorens, S., Salanova, M. ve Schaufeli, W. B. (2012). About the dark and bright sides of selfefficacy: Workaholism and work engagement. Spanish Journal of Psychology, 15(2), 688-701. doi:10.5209/rev_SJOP.2012.v15.n2.38883

Doğan, S. ve Aslan, M. (2018). Psikolojik sermaye, içsel motivasyon ve iş tatmini ilişkisi. Ömer Halis Demir Üniversitesi İktisadi ve İdari Bilimler Fakültesi Dergisi, 11(3)112-125. doi: 10.25287/ ohuiibf.423129

Doğan, T. ve Tel, F. D. (2011). Duwas işkoliklik ölçeği Türkçe formunun (DUWAS-TR) geçerlik ve güvenirliğinin incelenmesi. AIBBÜ, Ĕ̈itim Fakültesi Dergisi, 11(1), 61-69.

Efeoğlu, İ. E. (2006). İ̧s-aile yaşam çatışmasının iş stresi, iş doyumu ve örgütsel bağlllık üzerindeki etkileri: Illaç sektöründe bir araştırma. (Yayınlanmamış Doktora Tezi). Çukurova Üniversitesi, Adana.

Emhan A., Mete M. ve Emhan, A. (2012). Kamu ve özel sektör çalışanlarında işkoliklik ve obsesyon arasındaki ilişkinin incelenmesi. Dicle Tip Dergisi, 39(1), 75-79. doi:10.5798/ diclemedj.0921.2012.01.0098

Ersoy-Kart, M. (2005). Reliability and validity of the Workaholism Battery (WORK-BAT): Turkish form. Social Behavior and Personality, 33(6), 609-618. doi:10.2224/sbp.2005.33.6.609

Flowers, C. P. ve Robinson, B. E. (2002). A structural and discriminant analysis of the work addiction risk test. Educational and Psychological Measurement, 62(3), 517-526. doi:10.1177/00164402062003008

House, R. J. ve Rizzo, J. R. (1972). Role conflict and ambiguity as critical variables in a model of organizational behavior. Organizational Behavior and Human Performance, 7(3), 467-505. doi:10.1016/0030-5073(72)90030-X

Jenaabadi, H., Nejad, B. A., Abadi, F. S. M., Haghi, R. ve Hojatinasab, M. (2016). Relationship of workaholism with stress and job burnout of elementary school teachers. Health, 8(1), 1-8. doi:10.4236/health.2016.81001

Kanai, A., Wakabayashi, M. ve Fling, S. (1996). Workaholism among employees in Japanese corporations: An examination based on the Japanese version of the Workaholism Scales. Japanese Psychological Research, 38(4), 192-203. doi:10.1111/j.1468-5884.1996.tb00024.x

Machlowitz, M. (1980). Workaholics: Living with them, working with them. New York: Simon \& Schuster.

McMillan, L. H. W., Brady, E. C., O’Driscoll, M. P. ve Marsh, N. V. (2002). A multifaceted validation study of Spence and Robbins' (1992) Workaholism Battery. Journal of Occupational and Organizational Psychology, 75(3), 357-368. doi:10.1348/096317902320369758 
McMillan, L. H. W., O’Driscoll, M. P., Marsh, N. V. ve Brady, E. C. (2001). Under-standing workaholism: Data synthesis, theoretical critique, and future design strategies. International Journal of Stress Management, 8(2), 69-91. doi:10.1023/A:1009573129142

Molino, M. (2012). Workaholism: Definitions, measures, and dynamics (Yayımlanmamış Doktora Tezi). University of Torino, İtalya.

Molino, M., Bakker, A. B., ve Ghislieri, G. (2016). The role of workaholism in the job demandsresources model, Anxiety, Stress, \& Coping, 29(4), 400-414, doi: 10.1080/10615806.2015.1070833

Mudrack, P. E. (2006). Understanding workaholism: The case for behavioral tendencies. R.J. Burke (Ed.), Research companion to working time and work addiction içinde (s. 108-128). Northapton, MA: Edward Elgar Publishing.

Myers, N., Ahn, S. ve Jin, Y. (2011). Sample size and power estimates for a confirmatory factor analytic model in exercise and sport: A Monte Carlo approach. Research Quarterly for Exercise and Sport 82(3), 412-423. doi:10.1080/02701367.2011.10599773

Ng, T. W. H., Sorensen, K. L. ve Feldman, D. C. (2007). Dimensions, antecedents, and consequences of workaholism: A conceptual integration and extension. Journal of Organizational Behavior, 28, 111-136.

Oates, W. E. (1971). Confessions of a workaholic: The facts about work addiction. New York: World Publishing.

Orosz, G., Loránd, E., Dombi, E., Andreassen, C. S., Griffiths, M. D. ve Demetrovics, Z. (2016). Analyzing models of work addiction: Single factor and bi-factor models of the Bergen Work Addiction Scale. International Journal of Mental Health and Addiction, 14, 662-671.

Özsoy, E. (2018). Comparing the workaholism level of managers and non-managers. Business \& Management Studies: An International Journal, 6(4), 806-821. doi:10.15295/bmij.v6i4.294

Quinones, C. ve Griffiths, M. D. (2015). Addiction to work. A critical review of the workaholism construct and recommendations for assessment. Journal of Psychosocial Nursing and Mental Health Services, 53(10), 48-59. doi:10.3928/02793695-20150923-04

Robinson, B. E. (1989). Workaholism: Hidden legacies of adult children.Deerfield Beach, FL. Health Communications.

Robinson, B. E. (1999). The Work Addiction Risk Test: Development of a tentative measure of workaholism. Perceptual and Motor Skills, 88(1), 199-210. doi:10.2466/pms.1999.88.1.199

Robinson, B. E., Flowers, C., ve Ng, K. M. (2006). The relationship between workaholism and marital disaffection:Husbands'perspective.Family Journal, 14(3)213-220. doi.org/10.1177/1066480706287269

Robinson, B. E. ve Post, P. (1994). Validity of the work addiction risk test. Perceptual and Motor Skills, 78(1), 337-338. doi:10.2466/pms.1994.78.1.337

Schaufeli, W. B., Bakker, A. B., van der Heijden, F. M. M. A. ve Prins, J. T. (2009). Workaholism, burnout, and well-being among junior doctors: The mediating role of role conflict. Work and Stress, 23(2), 155-172. doi:10.1080/02678370902834021

Schaufeli, W. B., Shimazu, A. ve Taris, T. W. (2009). Being driven to work excessively hard, the evaluation of a two-factor measure of workaholism in the Netherlands and Japan. Cross-Cultural Research, 43(4), 320-348. doi:10.1177/1069397109337239

Schaufeli, W.B., Taris, T.W. ve Bakker, A. (2006). Dr. Jekyll and Mr. Hide: On the differences between work engagement and workaholism. R. Burke (Ed.), Research companion to working time and work addiction içinde (s. 193-217). Edward Elgar: Northampton, MA.

Schaufeli, W. B., Taris., T. W. ve van Rhenen, W. (2008). Workaholism, burnout, and engagement: Three of a kind or three different kinds of employee well-being? Applied Psychology: An International Review, 57(2), 173-203. doi:10.1111/j.1464-0597.2007.00285.x 
Schermelleh-Engel, K., Moosbrugger, H. ve Müler, H. (2003). Evaluating the fit of structural equation models: Tests of significance and descriptive goodness-of-fit measures. Methods of Psychological Research Online, 8(2),23-74.

Scott, K. S., Moore, K. S. ve Miceli, M. P. (1997). An exploration of the meaning and consequences of workaholism. Human Relations, 50(3), 287-314. doi:10.1177/001872679705000304

Shimazu, A. ve Schaufeli, W. B. (2009). Is workaholism good or bad for employee well-being? The distinctiveness of workaholism and work engagement among Japanese employees. Industrial Health, 47(5), 495-502. doi:10.2486/indhealth.47.495

Shimazu, A., Schaufeli, W. B., Kamiyama, K. ve Kawakami, N. (2015). Workaholism vs. work engagement: the two different predictors of future well-being and performance. International Journal of Behavioral Medicine, 22(1), 18-23. doi:10.1007/s12529-014-9410-x

Shimazu, A., Schaufeli, W. B. ve Taris, T. W. (2010). How does workaholism affect worker health and performance? The mediating role of coping. International Journal of Behavioral Medicine, 17(2), 154-160. doi:10.1007/s12529-010-9077-x

Sousa, V. D. ve Rojjanasrirat, W. (2011). Translation, adaptation and validation of instruments or scales for use in cross-cultural health care research: A clear and user-friendly guideline. Journal of Evaluation in Clinical Practice, 17(2), 268-274. doi:10.1111/j.1365-2753.2010.01434.x

Spence, J. T. ve Robbins, A. S. (1992). Workaholism - definition, measurement, and preliminary results. Journal of Personality Assessment, 58(1), 160-178. doi:10.1207/s15327752jpa5801_15

Srivastava, M. (2012). Stress, workaholism and job demands: A study of executives in Mumbai. NMIMS Management Review, 22(12), 94-116.

Steiger, J. H. (1980). Tests for comparing elements of a correlation matrix. Psychological Bulletin, 87(2), 245-251. doi:10.1037/0033-2909.87.2.245

Sussman, S. (2012). Workaholism: A Review. Journal of Addiction Research \& Therapy, 6(1). doi:10.4172/2155-6105.S6-001.

Taris, T. W., Schaufeli, W. B. ve Verhoeven, L. C. (2005). Workaholism in the Netherlands: Measurement and implications for job strain and work-nonwork conflict. Applied Psychology, 54(1), 37-60. doi:10.1111/j.1464-0597.2005.00195.x

van Beek, I, Q., Hu, Schaufeli, W. B., Taris, T. W. ve Schreurs, B. H. (2012). For fun, love or money. What drives workaholic, engaged and burned-out employees at work? Applied Psychology: An International Review, 61(1), 30-55. doi:10.1111/j.1464-0597.2011.00454.x

van Beek, I, Q., Hu, Schaufeli, W. B., Taris, T. W., ve Schreurs, B. H. (2012). For fun, love or money. What drives workaholic, engaged and burned-out employees at work? Applied Psychology: An International Review, 61(1), 30-55. https://doi.org/ 10.1111/j.1464-0597.2011.00454.x

van Someron, M. V., Barnard, Y. F. ve Sandberg, Y. A. C. (1994). The think aloud method: a practical guide to modelling cognitive processes. London: Academic Press.

Yeşiltaş, M. D. ve Ekici, E. (2017). İş akış deneyiminin kişilik özellikleri ve iş stresi ile ilişkisi: akademik personel üzerine bir araştırma. Çukurova Üniversitesi Sosyal Bilimler Enstitüsü Dergisi, 26(1), $1-11$.

Yıldırım, S. (2008). Muhasebe öğretim elemanları ve meslek mensuplarının mesleki stres düzeyi üzerine bir araştırma. Muhasebe ve Finansman Dergisi, 38(2) 153-162.

Yürür, Ş., ve Keser, A. (2011). İşe bağlı gerginlik ile iş tatmini ilişkisinde duygusal tükenmenin aracı rolü. Ankara Üniversitesi Siyasal Bilgiler Fakültesi Dergisi, 65(4) 165-194. 


\section{EK: Bergen İş Bağımlılığı Ölçeği’nin Türkçe Formu (BWAS-T)}

Aşağıda işinizle ilgili yedi soru bulunmaktadır. Lütfen bu soruları sizi en iyi yansıtacak şekilde "1-Hiçbir zaman, 2-Nadiren, 3-Bazen, 4-S1kl1kla, 5-Her zaman" cevap alternatiflerine göre cevaplayınız.

Geçtiğimiz yıl boyunca ne sıklıkla...

\begin{tabular}{clc}
\hline $\begin{array}{c}\text { Madde } \\
\text { Sırası }\end{array}$ & \multicolumn{1}{c}{ Maddeler } & $\begin{array}{c}\text { Bağımlılık } \\
\text { Bileşenleri }\end{array}$ \\
\hline BWAS-T1 & Çalışmak için nasıl daha fazla zaman yaratabileceğinizi düşündünüz? & Belirginlik \\
BWAS-T2 & İlk başta planladığınızdan daha fazla çalışmaya zaman harcadınız? & Tolerans \\
BWAS-T3 & $\begin{array}{l}\text { Suçluluk, kaygı, çaresizlik ve depresyon duygularını azaltmak için } \\
\text { çalıştınız? }\end{array}$ & $\begin{array}{c}\text { Duygu Durum } \\
\text { Düzenleme }\end{array}$ \\
BWAS-T4 & Başkaları size daha az çalışmanız gerektiğini söyledi? & Nüks Etme \\
BWAS-T5 & Çalışmanız engellendiği için strese girdiniz? & Yoksunluk \\
BWAS-T6 & İşinizi hobileriniz, boş zaman aktiviteleriniz ve egzersizlerinizden & Çatışma \\
& önce tuttunuz? & Problem Yaşama \\
\hline BWAS-T7 & Sağlığınızı olumsuz etkileyecek düzeyde çok çalıştınız? & \\
\hline
\end{tabular}


